\title{
Study of Protein Modification by 4-Hydroxy-2- Nonenal and Other Short Chain Aldehydes Analyzed by Electrospray Ionization Tandem Mass Spectrometry
}

\author{
François Fenaille and Philippe A. Guy \\ Department of Quality and Safety Assurance, Nestlé Research Center, Nestec Ltd., Lausanne, Switzerland
}

Jean-Claude Tabet

Laboratoire de Chimie Structurale Organique et Biologique, University Pierre and Marie Curie, Paris, France

\begin{abstract}
A convenient way to study lipid oxidation products-modified proteins by means of suitable model systems has been investigated. As a model peptide, the oxidized B chain of insulin has been chemically modified by either 4-hydroxy-2-nonenal (HNE) or hexanal and the extent, sites, and structure of modifications were assessed by electrospray mass spectrometry. A reduction step, using either $\mathrm{NaCNBH}_{3}$ or $\mathrm{NaBH}_{4}$, was also studied to stabilize the alkylated compounds. From the data gathered, it appeared that $\mathrm{NaCNBH}_{3}$, when added at the beginning of incubation, dramatically influenced the HNE-induced modifications in terms of the addition mechanism (Schiff base formation instead of Michael addition) but also of the amino acid residues modified ( $\mathrm{N}$-terminal amino acid instead of histidine residues). However, by reducing the HNE-adducted species at the end of the reaction with $\mathrm{NaBH}_{4}$, the fragment ions obtained in the product ion scan experiments become more stable and thus, easier to interpret in terms of origin and mechanism involved. With regard to hexanal induced modifications, we have observed that hexanal addition under reductive conditions led to an extensive modification of the peptide backbone. Moreover, as confirmed by "in-source" collision followed by collision induced dissociation (CID) experiments on selected precursor ions (pseudo-MS ${ }^{3}$ experiments), $\mathrm{N}, \mathrm{N}$-di-alkylations were first observed on the $\mathrm{N}$-terminal residue and further on $\mathrm{Lys}_{29}$ residue. On the other hand, compared to the native peptide, no significant changes in MS/MS fragmentation patterns ( $b$ and y ions series) were observed whatever the basic site modified by the aldehyde-addition. (J Am Soc Mass Spectrom 2003, 14, 215-226) (C) 2003 American Society for Mass Spectrometry
\end{abstract}

$\mathrm{L}$ ipid oxidation is a major cause of quality deterioration during the processing/storage of lipidrich foods, thus limiting their shelf-life stability. Hydroperoxides, the primary products of lipid oxidation, are colorless, tasteless and odorless. The breakdown products of these peroxides yield a complex mixture of low molecular weight compounds with distinctive odor and flavor characteristics, including alkanes, alkenes, aldehydes, ketones, alcohol, esters, and acids [1,2]. Among all these oxidation products, aldehydes belong to the most important off-flavor compounds of rancidic fats and oils. Low molecular alkanals, (hydroxy) alkenals and alkadienals are known to readily react with nucleophilic residues of food proteins $[3,4]$. Such chemical modifications represent an impor-

Published online January 24, 2003

Address reprint requests to Dr. P. A. Guy, Department of Quality and Safety Assurance, Nestlé Research Center, Nestec Ltd., Vers-Chez-les-Blanc, P.O. Box 44, 1000 Lausanne 26, Switzerland. E-mail: philippe.guy@ rdls.nestle.com tant deteriorative mechanism in the processing and storage of foods causing loss in color, flavor, functional/physical properties and nutritive values [5]. Moreover, in biological systems, numerous disease states (cancer, cardiovascular disease,...) have been associated with lipid-modified proteins [6, 7].

Therefore, these reactions and interactions are of high interest in food science as well as in other disciplines. As described earlier, aldehydes are able to react with nitrogenous nucleophiles such as lysine, histidine, or cysteine to form Schiff bases (imines) whereas alkenals and hydroxy-alkenals could also undergo Michael (1-4) addition (Figure 1) [7-11]. Among these different lipid oxidation products, 4-hydroxy-2-nonenal (HNE) has received particular attention and was found to occur mainly on histidine or lysine residues via a Michael addition [8, 12-14]. Indeed, Bruenner et al. have reported the mass spectrometric analysis of two HNE-modified model proteins ( $\beta$-lactoglobulin B and human hemoglobin) and thus showed, by comparison 


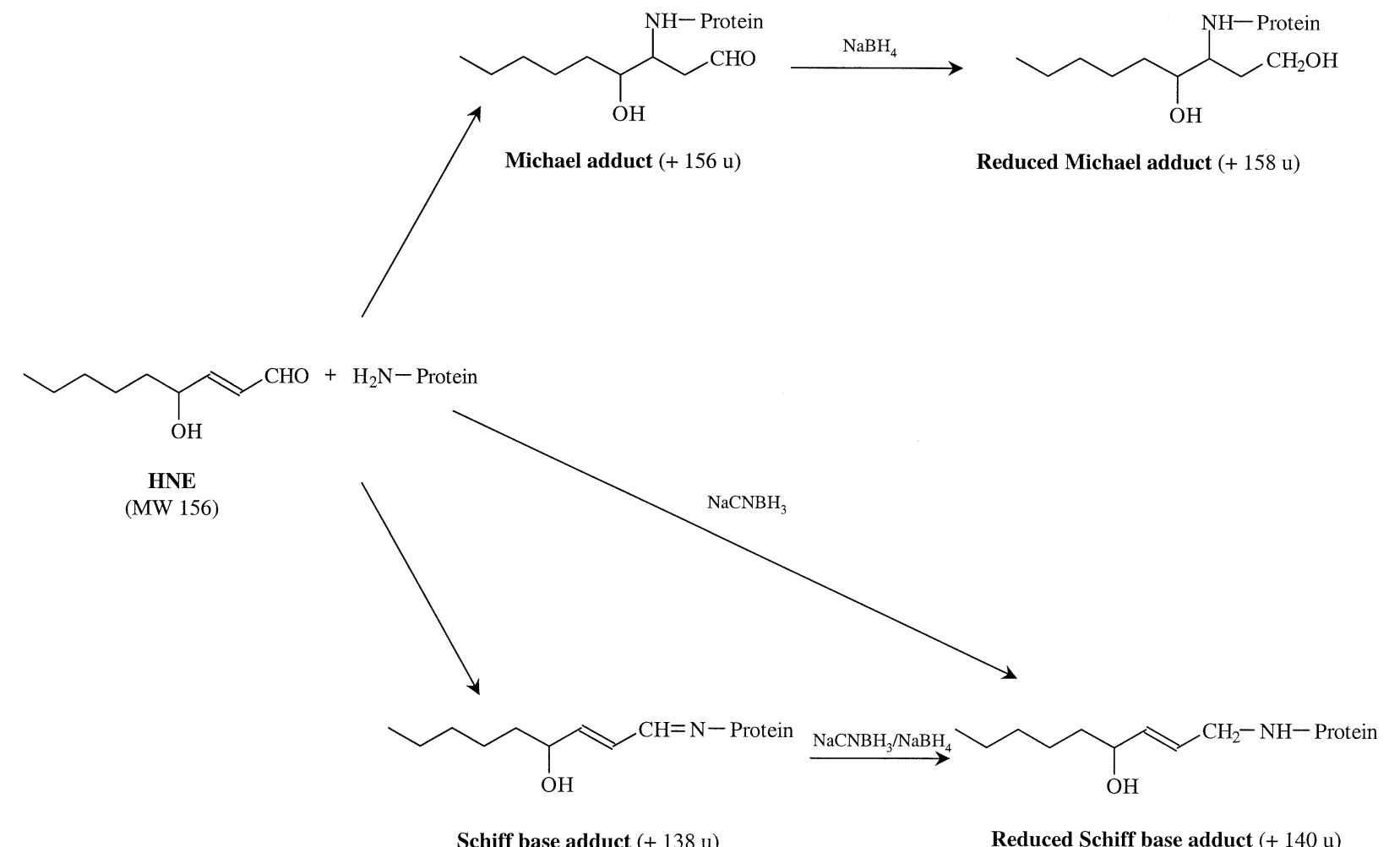

Figure 1. Mechanisms for the formation and stabilization of the HNE Michael and Schiff base adducts.

of the molecular masses, the preponderance of the Michael addition over the Schiff base condensation [7]. Moreover, the histidine residues were identified as the main target of HNE modification in human hemoglobin as well as $\beta$-lactoglobulin B [7], apomyoglobin [14], or subunit VIII of bovine heart cytochrome $c$ oxidase [12]. In contrast, lysine residues seem to be the predominantly HNE-modified residues in glucose-6-phosphate dehydrogenase $[15,16]$. To our knowledge, the literature does not report some dramatic changes in CID fragmentation patterns ( $b$ or y fragment ions series) when proteins are modified by HNE as well as by other aldehydes originating from lipid oxidation.

Depending on both the aldehyde and amino acid considered, the modified residues could exhibit a propensity to hydrolysis, thus making necessary their reduction to the corresponding stable secondary amine or alcohol prior to analysis. For obtaining stable aldehyde-modified proteins or peptides, reductive alkylation conditions are often employed by incubating the substrates in the presence of sodium cyanoborohydride $\left(\mathrm{NaCNBH}_{3}\right)$ under alkaline $\mathrm{pH}$ conditions to reduce the imines immediately upon formation without reducing unreacted aldehydes. Such approach has previously been used to evaluate the extent, site, structure and potential changes in physical and/or nutritional properties of proteins modified by aldehydes or aldoses
[16-18] as well as to synthetize antigens for further antibody production [19]. As an alternative, sodium borohydride $\left(\mathrm{NaBH}_{4}\right)$ could also be used at the end of the reaction $[8,20,21]$. Under slightly alkaline conditions, this reagent will lead to the reduction of both the modified amino acid residues (unlike Schiff base and Michael adducts) and the remaining unreacted aldehydes, thus acting as a reaction quencher [22]. The reduced modified residues exhibit improved stability since they are resistant to acid hydrolysis conditions $\left(\mathrm{HCl} 6 \mathrm{~N}\right.$ at $110{ }^{\circ} \mathrm{C}$ during $\left.20-24 \mathrm{~h}\right)[8,21]$. Therefore, a reductive stabilization is of high interest if an aciddriven cleavage of proteins is envisioned to quantify the extent of such modifications.

The goal of this work was to identify and to further characterize by electrospray ionization mass spectrometry (ESI-MS) and MS/MS experiments the protein modifications formed upon aldehyde treatment. Moreover, we have also investigated the utilization of reductive stabilization and its influence in terms of chemical and gas phase ion behavior. For such purpose, we have studied the chemical modifications of a model peptide (oxidized insulin B chain) by two different aldehydic compounds: (1) 4-hydroxy-2-nonenal, a cytotoxic hydroxyalkenal often measured as indicator of in vivo oxidative stress $[8,23]$ and (2) hexanal, which is commonly recognized as a marker of food quality $[1,19,24]$. 


\section{Experimental}

\section{Materials}

Oxidized insulin B chain and octanal were obtained from Sigma (Büchs, Switzerland). Hexanal, sodium cyanoborohydride, and sodium borohydride were purchased from Aldrich (Büchs, Switzerland) whereas butanal was from Fluka (Büchs, Switzerland). Finally, 4-hydroxy-2-nonenal was obtained from Alexis (Laufelfingen, Switzerland). All other chemical reagents were of analytical or HPLC grade.

\section{Sample Preparation}

Oxidized insulin B chain (58 $\mu \mathrm{M}, \mathrm{M} 3495.9 \mathrm{Da})$ was incubated overnight at $37^{\circ} \mathrm{C}$ in an aqueous solution of $0.3 \mathrm{mM}$ HNE or $2.8 \mathrm{mM}$ saturated aldehydes (butanal, hexanal, and octanal) buffered with $50 \mathrm{mM}$ phosphate buffer $\mathrm{pH} 7.4$ (final volume, $0.5 \mathrm{ml}$ ). These experiments were performed both in the absence and in the presence of $\mathrm{NaCNBH}_{3}$ (20 mM in phosphate buffer). For $\mathrm{NaBH}_{4}$ reduction, $100 \mu \mathrm{l}$ of a $0.1 \mathrm{M}$ solution in $0.1 \mathrm{~N} \mathrm{NaOH}$ were added at the end of the incubation and the mixtures were further incubated for $1 \mathrm{~h}$ at $37^{\circ} \mathrm{C}$. After cooling down at room temperature, the resulting modified peptides were purified/desalted chromatographically on a reusable reverse phase cartridge (Peptide Macrotrap, Michrom Bioressources, Pleasanton, CA). The cartridge was washed with $0.1 \%$ acetic acid and the peptides were recovered by elution with $200 \mu$ l of methanol/water $(80: 20, \mathrm{vol} / \mathrm{vol})$ containing $0.1 \%$ acetic acid.

\section{Mass Spectrometry}

MS analyses were performed on a TSQ 7000 mass spectrometer equipped with an API 2 interface in positive electrospray ionization mode (ThermoFinnigan, San Jose, CA). The spray voltage was set at $4.0 \mathrm{kV}$ with a capillary temperature of $250{ }^{\circ} \mathrm{C}$ and a sheath gas (nitrogen) pressure of 80 psi. After elution from the desalting Macrotrap peptide cartridge, the peptides mixture was infused at a flow rate of $3 \mu \mathrm{l} / \mathrm{min}$ into the ESI source using a syringe pump (Harvard Apparatus, South Natick, MA). Full scan positive mass spectra were recorded by scanning a $\mathrm{m} / \mathrm{z}$ range of 500-2000 (mass unit resolution) with a scan time of 2 s. Low energy CID experiments were achieved on multiply charged species at different collision energies $\left(\mathrm{E}_{\mathrm{Lab}}\right.$ 20-45 eV), using argon as collision gas at a pressure of 2.8 mTorr $(1$ torr $=133.3 \mathrm{~Pa})$. Moreover, for the CID experiments performed after "in-source" collision (pseudo-MS ${ }^{3}$ ) [25], a voltage of 50-70 V was applied to the octapole (in-source) to generate unspecific primary fragment ions that were then selected in the first quadrupole and further collisioned with argon (pressure of 2.8 mTorr, $\mathrm{E}_{\mathrm{Lab}} 20-30 \mathrm{eV}$ ) in the second quadrupole. Typically, mass spectra and CID spectra were accumu- lated into a single data file for 1-5 min. Data processing was performed using the Finnigan Xcalibur software.

\section{Results and Discussion}

\section{HNE-Modified Oxidized Insulin B Chain}

Oxidized insulin B chain was chosen as model peptide because it contains four basic residues $\left(\mathrm{His}_{5}, \mathrm{His}_{10}\right.$, $\operatorname{Arg}_{22}$, and $\mathrm{Lys}_{29}$ ) plus the N-terminal. The two cysteine residues are blocked as cysteic acids, avoiding the possibility of dimerization or peptide aggregation (peptide sequence is represented in Figure 2). Figure 2 summarizes the adducts formed after incubating the peptide with $\mathrm{HNE}$ in the presence and in the absence of reductive agent (i.e., $\mathrm{NaCNBH}_{3}$ or $\mathrm{NaBH}_{4}$ ).

When oxidized insulin $\mathrm{B}$ chain was simply reacted with HNE, two adducts corresponding to a mass increase of $156 \mathrm{u}$ were observed (M 3652.0 and 3808.0 Da). The appearance of such mass increments confirms the addition of two HNE moieties via a Michael mechanism (Figure 1). To identify the sites of modification, CID experiments were performed on the respective triply charged categories of these two HNE-adducted species (i.e., $m / z 1218.3$ and 1270.3). Modified fragment ions are labeled with an asterisk and according to the nomenclature of peptide fragmentation [26]. Thus, $\mathrm{His}_{5}$ was the modified residue when the addition of only one HNE molecule occurs, proven by the appearance of the $\mathrm{b}_{5}$ ion containing one HNE moiety (Figure 3a), whereas both $\mathrm{His}_{5}$ and $\mathrm{His}_{10}$ were found to be modified in the case of di-alkylation (data not shown). As previously described by Bolgar and Gaskell [14], HNE-modified histidine residues give rise to an intense immonium ion at $m / z 266$ (noted $\mathrm{H}^{*}$ ), thus confirming the presence of an HNE molecule. Moreover, beside this typical immonium ion, a fragment ion corresponding to the protonated dehydrated HNE moiety can be clearly seen at $\mathrm{m} / \mathrm{z}$ 139 in the product ion mass spectrum (Figure 3a). These two typical fragment ions $(\mathrm{m} / \mathrm{z} 139$ and 266) observed in such product ion scan analysis can be very helpful to assess or confirm the presence of HNE-adducted peptides, and consequently to characterize the involvement of an histidine residue.

Likewise, a subsequent reduction by $\mathrm{NaBH}_{4}$ of the different HNE-modified species, was performed to improve their stability and also to confirm the identity of the adducts obtained. Indeed, under slightly alkaline conditions, either $\mathrm{NaCNBH}_{3}$ or $\mathrm{NaBH}_{4}$ effectively reduced the imine whereas only Michael adducts would be sensitive to $\mathrm{NaBH}_{4}$ reduction [27]. In case of HNE Michael adducts, this reduction step results in $158 \mathrm{u}$ mass increments (Figure 1). Figure $3 b$ represents the CID mass spectrum of the first reduced Michael adduct obtained by selecting the triply charged species $(\mathrm{m} / \mathrm{z}$ 1219.0). By reducing these HNE-adducted molecules at the end of the alkylation reaction, the resulting modified fragment ions become more stable, thus easier to localize the modification (cf. modified fragment ions 


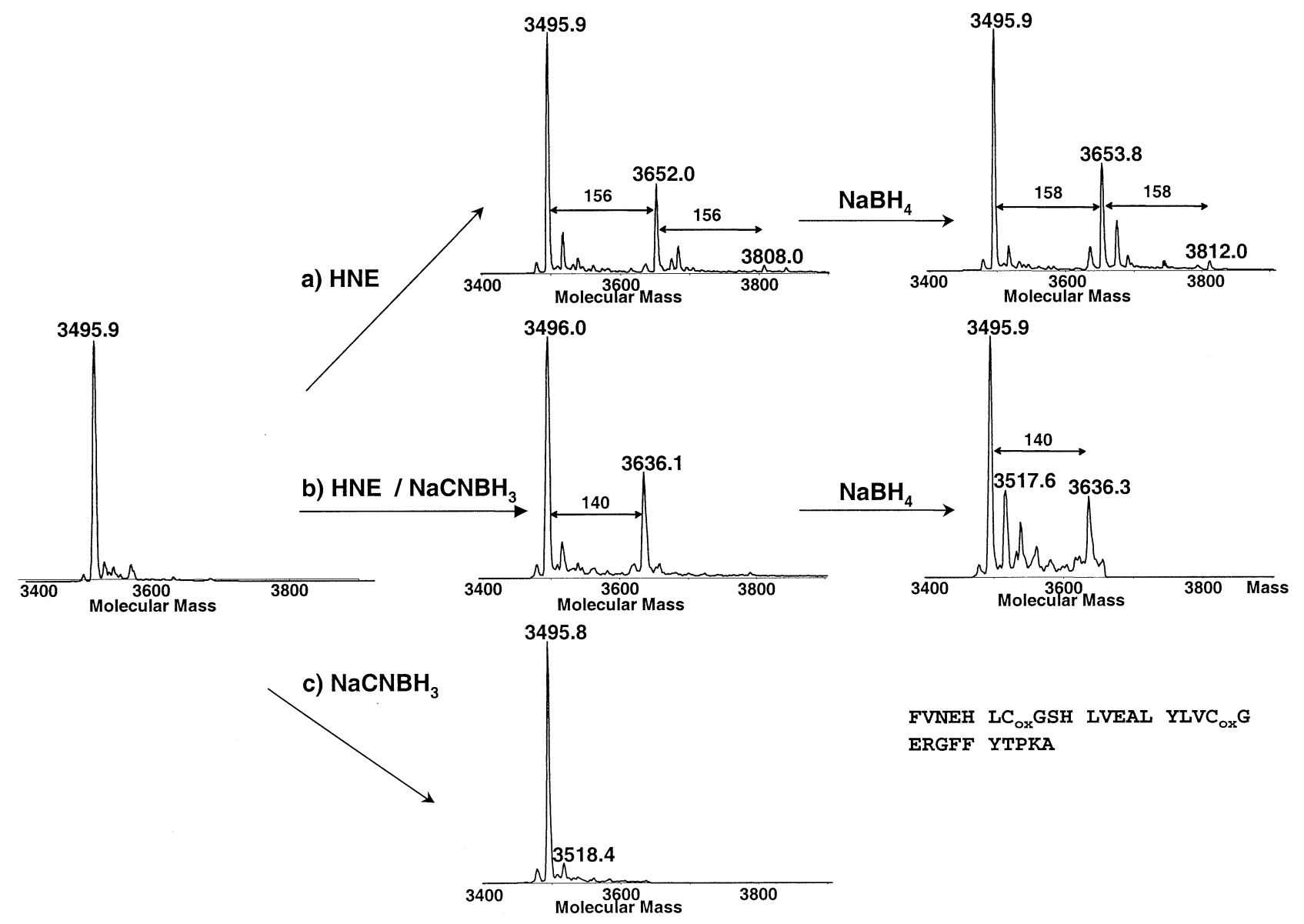

Figure 2. Deconvoluted ESI mass spectra of HNE-modified oxidized insulin B peptide chain obtained under (a) normal and (b and $\mathbf{c}$ ) reductive conditions. The peptide sequence has been represented in the one letter code nomenclature.

labeled with an asterisk). Moreover, it should be noted that $\mathrm{NaBH}_{4}$ reduction leads (1) to the formation of a prominent reduced HNE histidine immonium ion at $\mathrm{m} / \mathrm{z} 268$ (instead of $\mathrm{m} / \mathrm{z} 266$ in the absence of reduction) and (2) to the disappearance of the protonated dehydrated HNE fragment ion previously observed at $\mathrm{m} / \mathrm{z}$ 139. These differences regarding the observed fragment ions demonstrate the HNE Michael adduct instability (under non-reductive conditions) under our CID experimental conditions. This feature has also been observed by studying other HNE modified model peptides under low energy collision-induced conditions. Thus, $\mathrm{NaBH}_{4}$ reduction appeared to modify the fragmentation behavior of the HNE-His residue (Michael adduct) by stabilization of the derivative and further suppression of the loss of HNE moiety under the CID conditions used.

When oxidized insulin B chain was modified by HNE under non reductive conditions, the HNE modification occurred predominantly by Michael addition rather than Schiff base formation. On the contrary, when $\mathrm{NaCNBH}_{3}$ is added at the beginning of the incubation (to immediately reduce imines upon their formation), a single adduct, differing by $140 \mathrm{u}$ from the native peptide (Figure 1), was observed (M 3636.1 Da) and could be attributed to a reduced Schiff base HNE adduct (Figure $2 b$ ). Moreover, this HNE adduct has been characterized on the $\mathrm{N}$-terminal Phe residue using CID experiment by selecting the triply charged species at $\mathrm{m} / \mathrm{z} 1213.7$ (Figure 3c). Among other discriminant fragment ions, $m / z 260$ corresponds to the Phe $(\mathrm{N}$-ter) immonium ion modified by HNE via a Schiff base mechanism. These results demonstrate that $\mathrm{NaCNBH}_{3}$ orientates the mechanism of HNE addition and thus, changes the site(s) of modification. As a control experiment, incubation of native oxidized insulin B chain was performed with the reductive agent, which enabled to verify the absence of side reaction products due the native peptide itself (Figure 2c).

All the results gathered on HNE adduction revealed that $\mathrm{NaCNBH}_{3}$ orientates the reaction toward the Schiff base addition and also induces preferential modification of the N-terminal residue (instead of histidine residues in the absence of reducing agent). Moreover, the comparison of the ESI mass spectra acquired on the native oxidized insulin B chain and on the HNEmodified species, revealed no significant difference either in the observed charge states $(+2,+3,+4)$ or in their relative abundances (data not shown). Therefore, 
a)
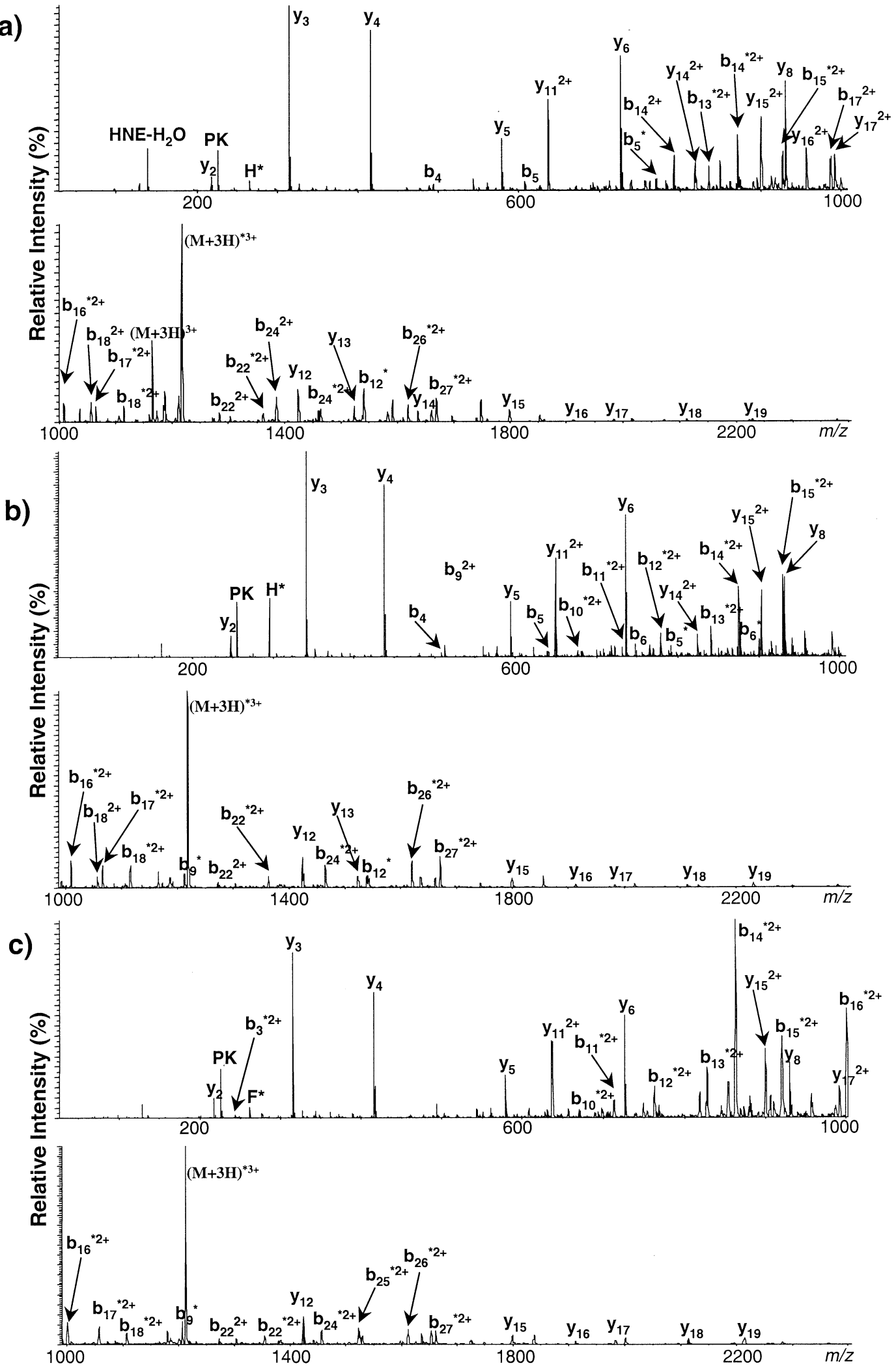

Figure 3. CID mass spectra of HNE-modified oxidized insulin B chain obtained by selecting the triply charged species of (a) $\mathrm{m} / \mathrm{z} 1218.3$ for HNE modification without reducing agent, (b) $\mathrm{m} / \mathrm{z} 1219.0$ for HNE modification followed by $\mathrm{NaBH}_{4}$ treatment, and (c) $\mathrm{m} / \mathrm{z} 1213.7$ for HNE modification in the presence of $\mathrm{NaCNBH}_{3}$. Modified fragment ions are labeled with an asterisk and according to the nomenclature of peptide fragmentation [26]. 

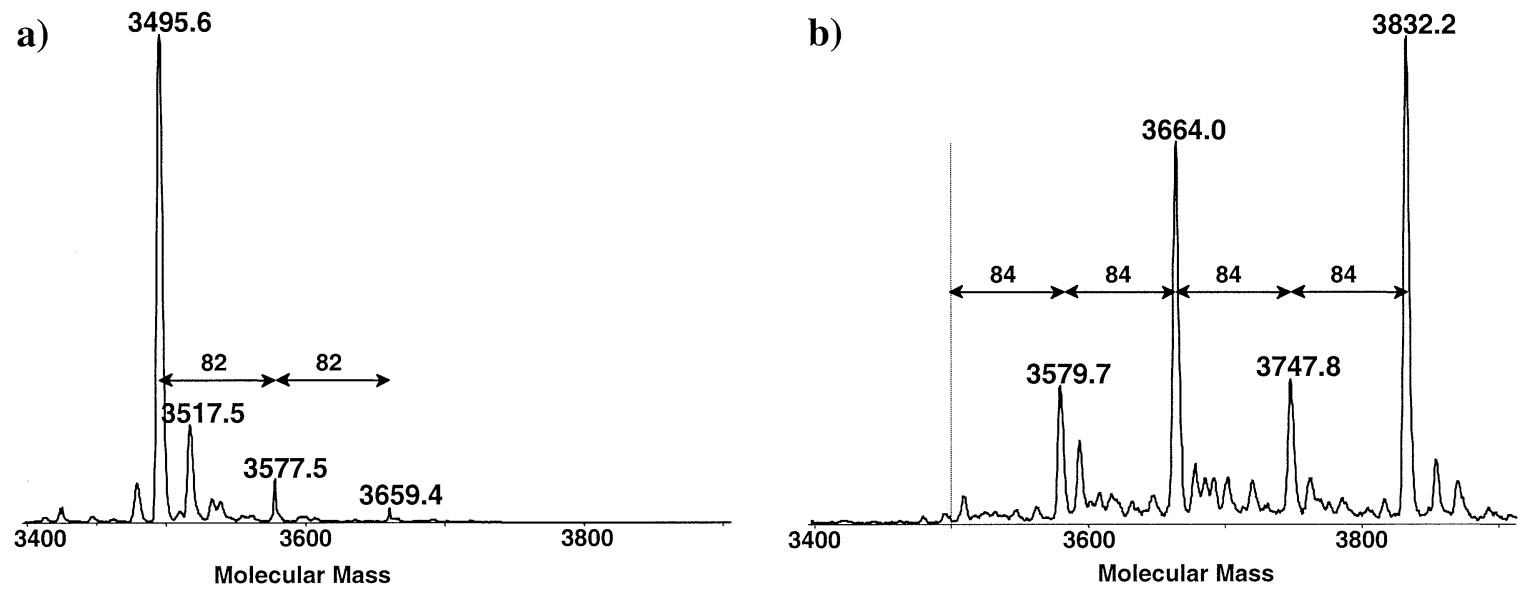

Figure 4. Deconvoluted ESI mass spectra of oxidized insulin B chain hexanal treated (a) in the absence and (b) in the presence of $\mathrm{NaCNBH}_{3}$.

this type of adduct does not affect the protonation orientation of this peptide during the ESIMS analysis. Furthermore, the HNE modification of either the Nterminal or histidine amino acid residues did not lead to CID fragmentations fundamentally different, in terms of ions distribution in $\mathrm{b}$ and $\mathrm{y}$ fragment ions series, compared to the data previously obtained for the native oxidized B chain of insulin. Therefore, HNE modification does not seem to modify the proton transfer occurring during the peptide fragmentation. It could be assumed that a proton was not initially localized on the $\mathrm{His}_{5}$ residue. In order to evaluate the histidine positioning influence on CID, Willard and Kinter have studied a synthetic peptide containing one histidine in position 4 and suggested that both $\mathrm{N}$-terminal and histidine residues should be derivatized (with diethylpyrocarbonate) to observe significant changes in terms of CID [28]. Therefore, it seems logical that the more significant effects on CID will be observed for a higher number of alkylated basic sites or on a folded protein.

In a second step, we have studied the effect of such reductive alkylation on the saturated aldehydes addition to oxidized B chain of insulin, to assess its influence when a single addition mechanism could occur (Schiff base mechanism only).

\section{Hexanal-Modified Oxidized Insulin B Chain}

Figure 4 shows the deconvoluted ESI mass spectra of oxidized insulin $\mathrm{B}$ chain treated with hexanal in absence and presence of $\mathrm{NaCNBH}_{3}$. When no reductive agent was added (Figure 4a), the major ions correspond to the native peptide (M 3495.6 Da) in addition to one and two hexanal-modified species (M 3577.5 and $3659.4 \mathrm{Da}$, respectively). Some cationized sodium adducts were also observed for the native peptide (M 3517.5 Da). CID experiments were performed on the triply charged species of the one and two hexanal-modified species (i.e., $\mathrm{m} / \mathrm{z} 1193.5$ and 1220.8 , respectively) and their respective fragmentation patterns confirmed the attach- ment of the aldehyde moieties to the N-terminal $\mathrm{Phe}_{1}$ and $\mathrm{Lys}_{29}$ residues, but predominantly on the N-terminal (data not shown). Moreover, the observed relative abundances of these two hexanal-adducted peptides were rather low when compared to those of HNEmodified species, thus underlining the poorer reactivity of the saturated aldehydes in comparison to unsaturated ones. However, incubation of hexanal performed in the presence of $\mathrm{NaCNBH}_{3}$ resulted in a contrary situation (Figure $4 b$ ). Indeed, this reagent seems to act as a catalyst, thus generating up to four hexanal adducts characterized by $84 \mathrm{u}$ increments. The obtained deconvoluted ESI mass spectrum apparently exhibits a relative distribution of the four adducted forms which could be characteristic of a particular kinetic of addition. Actually, such trend could suggest that hexanal modification occurs only on two distinct amino acid residues.

Thus, CID experiments were performed on the respective triply charged species $(\mathrm{m} / \mathrm{z} 1222.5$ and 1278.6) (Figure 5). The CID spectra of the oxidized insulin B chain modified by two and four hexanal moieties gave rise to two couples of abundant ions observed at $\mathrm{m} / \mathrm{z}$ 204.2, 288.3, and $\mathrm{m} / \mathrm{z}$ 399.4, 483.5 (Figure $5 \mathrm{a}$ and b). The first two fragment ions (i.e., $\mathrm{m} / \mathrm{z} 204.2$ and 288.3) could be attributed to immonium ions of the $\mathrm{N}$-terminal $\mathrm{Phe}_{1}$ bound with one and two hexanal moieties, respectively. On the other hand, the second couple of ions observed at $m / z 399.4$ and 483.5 were assigned to the $y_{3}$ fragment ions plus one and two hexanal moieties, respectively. The occurrence of such mono- and di-alkylations is totally conceivable since the reduction of the immonium intermediate by $\mathrm{BH}_{3} \mathrm{CN}^{-}$is a rapid reaction at $\mathrm{pH}$ ca. 7.0 [29].

It has been previously reported in the literature that low energy product ion spectra from a number of peptides, obtained by "in-source" collision, were comparable in quality and information content with those obtained by low energy CID in a quadrupole collision cell [30-32]. Therefore, results from CID experiments 


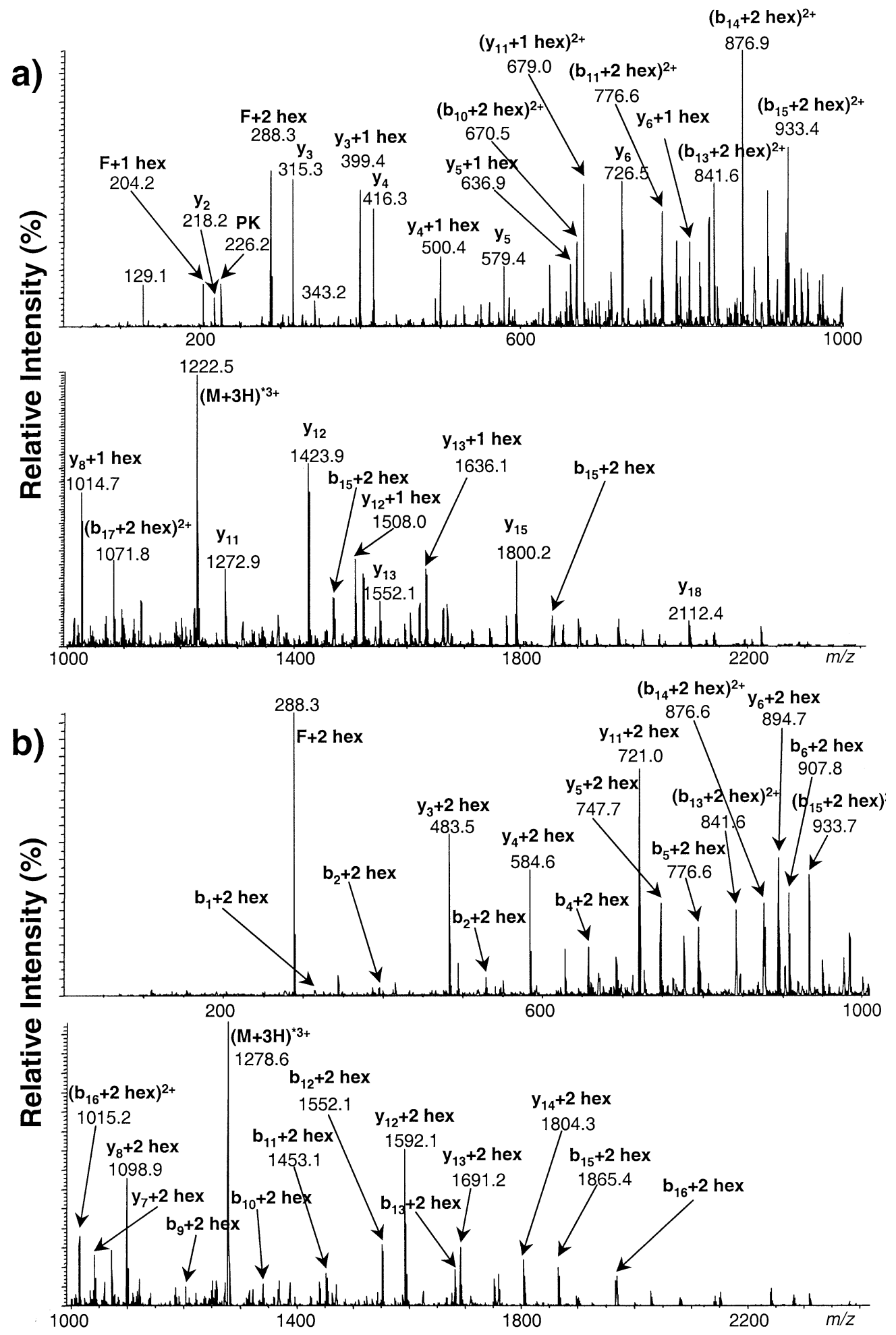

Figure 5. CID spectra of hexanal-modified oxidized insulin $\mathrm{B}$ chain in the presence of $\mathrm{NaCNBH}_{3}$ obtained by selecting the triply charged species of (a) $\mathrm{m} / \mathrm{z} 1222.5$, and (b) $\mathrm{m} / \mathrm{z}$ 1278.6, corresponding to the addition of two and four hexanal molecules, respectively. Hexanal adducts have been abbreviated

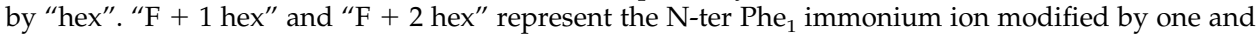
two hexanal moieties, respectively.

performed on "in-source" generated ions would be very similar to those obtained using a hybrid instrument (BEQQ) or a pentaquadrupole [25, 33]. Thus, to further confirm the presence of one and two hexanal attachments at both N-terminal $\mathrm{Phe}_{1}$ and $\mathrm{Lys}_{29}$, "insource" collision followed by CID experiments were 


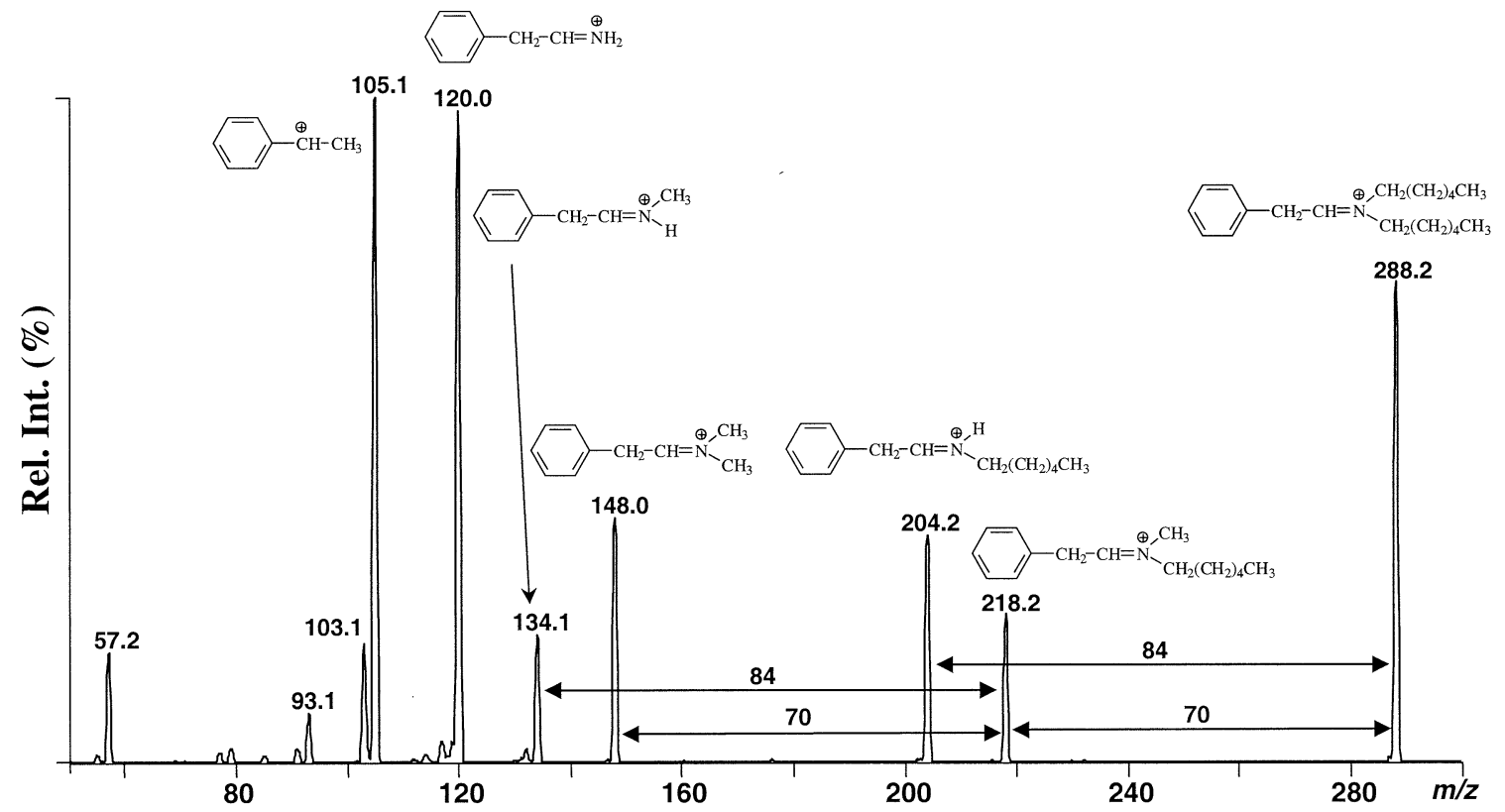

Figure 6. CID spectra of hexanal-modified species obtained by selecting $\mathrm{m} / \mathrm{z} 288.3$ after "in-source" collision.

performed by selecting the corresponding ions. The different fragment ions observed from the product ion scan of $m / z 288.3$ (Figure 6) have been characterized and clearly show the attachment of two hexanal moieties on the N-terminal of $\mathrm{Phe}_{1}$. This CID spectrum exhibits two losses of $70 \mathrm{u}$ and $84 \mathrm{u}(288.2 \rightarrow 218.2,288.2 \rightarrow$ 204.2, and $218.2 \rightarrow 148.0,218.2 \rightarrow 134.1)$ characteristic of the $\mathrm{N}, \mathrm{N}$-di-hexyl chains fragmentations. Figure $7 \mathrm{a}-\mathrm{c}$ repre- sent the "in-source" collision followed by CID analysis of $\mathrm{m} / \mathrm{z} 315.0,399.3$, and 483.5 corresponding to intact, mono-alkylated- and di-alkylated $\mathrm{y}_{3}$ fragment ions (i.e., PKA peptidic chain), respectively. Interpretation of these CID spectra confirms that $\mathrm{N}^{\varepsilon}$-mono-alkylation and $\mathrm{N}^{\varepsilon}, \mathrm{N}^{\varepsilon}$-di-alkylation have occurred on the $\mathrm{Lys}_{29}$ residue $\left(\mathrm{m} / \mathrm{z} 310.3\right.$ and 394.5 correspond to $\boldsymbol{b}_{2}{ }^{*}$ and $\boldsymbol{b}_{2}{ }^{* *}$, respectively). Unfortunately, no characteristic immo-

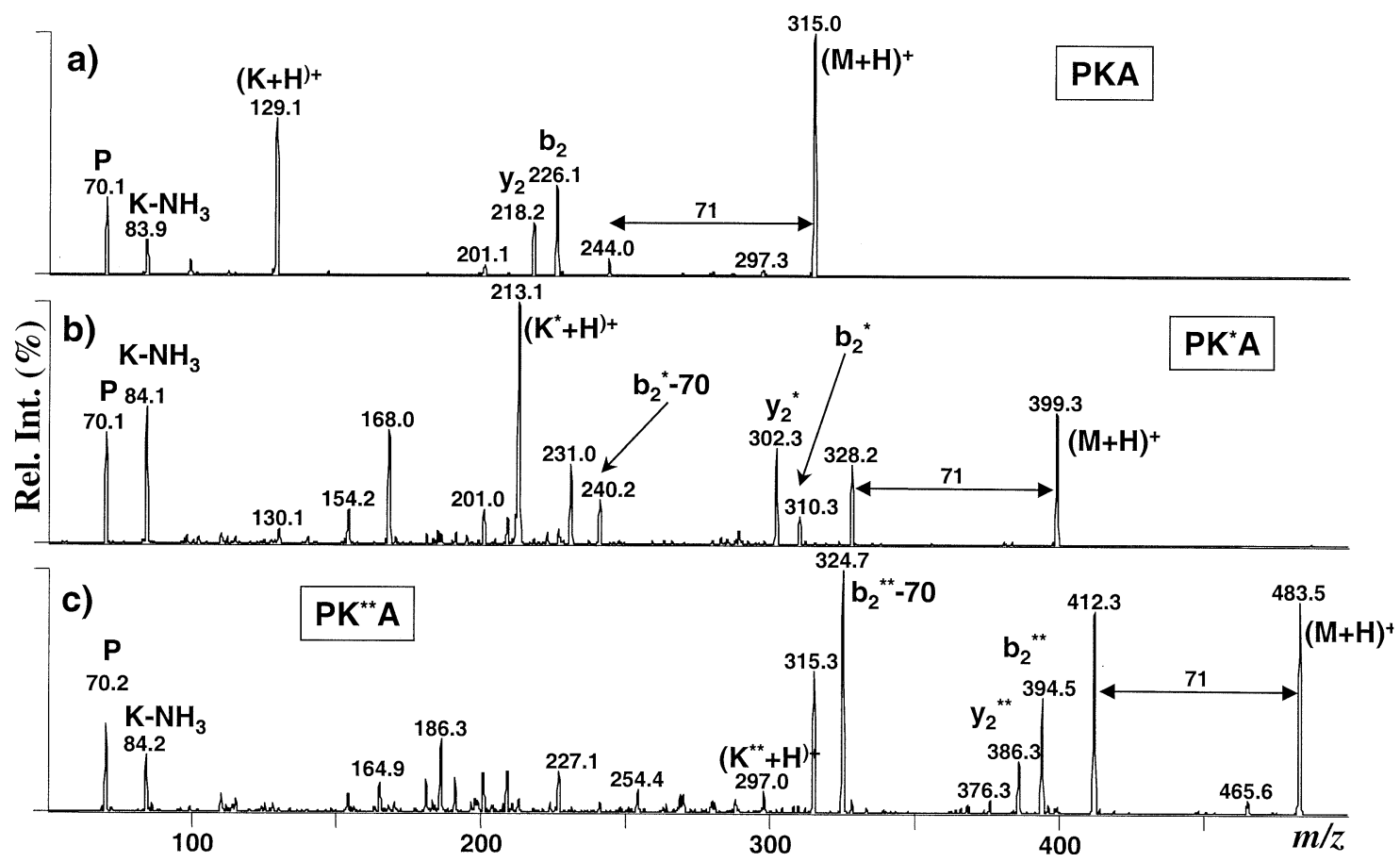

Figure 7. CID spectra of hexanal-modified species obtained by selecting (a) $\mathrm{m} / \mathrm{z} 315.3$, (b) $\mathrm{m} / \mathrm{z} 399.4$, and (c) $m / z$ 483.5, after "ion-source" collision. 
nium ion of lysine-hexanal was observed. Moreover, as already noted for the di-alkylation of $\mathrm{Phe}_{1}$, a loss of $70 \mathrm{u}$ was found for the $b_{2}{ }^{*}$ and $b_{2}{ }^{* *}$ fragment ions (giving rise to $m / z 240.2$ and 324.7, respectively), corresponding to a partial loss of the hexyl chain. Finally, a loss of $71 \mathrm{u}$ was also observed for the three CID spectra giving rise to fragment ions at $m / z 244.0,328.2$, and 412.3 for the native-, mono-alkylated- and di-alkylated- $y_{3}$ CID spectra, respectively. This typical loss on the C-terminus, in this case $\mathrm{Ala}_{30}$, has already been reported in the literature and explained as resulting from a shift of the hydroxyl group from the C-terminal carboxylic function [34-36]. Although this mechanism was first reported under high collision energy (tandem sector instrument), a similar pattern was observed here under low collision energy conditions. The fragmentation pathway (i.e., loss of $71 \mathrm{u}$ ) illustrated in Figure 8 for the CID experiment of $m / z 483.5$ (di-alkylated PKA) is similar for the native- and mono-alkylated- $y_{3}$ ion species.

The alkylation kinetic of hexanal towards oxidized insulin B chain has then been evaluated under reductive conditions. The hexanal modification in the presence of $\mathrm{NaCNBH}_{3}$ is a rapid phenomenon since after $30 \mathrm{~min}$, no native peptide remains in the reaction mixture (Figure $9 b$ ). As previously underlined, $\mathrm{Phe}_{1}$ and $\mathrm{Lys}_{29}$ constitute the alkylated sites. CID experiments performed on the triply charged species of the different hexanalmodified peptides $(\mathrm{m} / \mathrm{z} 1194.2,1222.2,1250.2$, and 1278.4) revealed that (1) the first hexanal molecule was exclusively added to the N-terminal $\mathrm{Phe}_{1}$, (2) the doubly modified peptide contained a mixture of di-alkylated Phe and mono-alkylated species of Phe and Lys but no di-alkylated Lys residues, (3) the third modified form was mainly di-alkylated on $\mathrm{Phe}_{1}$ and monoalkylated on $\mathrm{Lys}_{29}$ residue whereas (4) the last modified peptide was di-alkylated on both $\mathrm{Phe}_{1}$ and $\mathrm{Lys}_{29}$ residues. These observations suggest that $\operatorname{Lys}_{29}$ is a less reactive residue compared to $\mathrm{Phe}_{1}$, and thus corresponds to the limiting factor of the hexanal alkylation process. However, we can reasonably assume that the tetra-alkylated peptide will be the only form observed after a prolonged incubation period. On the other hand, it should be noted that the same trend of alkylation was also observed for butanal and octanal (Figure 10). In this case, addition of butanal and octanal molecules to the peptide leads to a mass increase of 56 and $112 \mathrm{u}$, respectively. Moreover, when incubation of oxidized insulin B chain is performed under competitive conditions, i.e., with equimolar amounts of butanal, hexanal, and octanal, several modified species resulting from the different aldehydes were observed in similar ratios (data not shown). These results give evidence that neither competition nor alkyl chain length effects were encountered, in the liquid phase, in the presence of $\mathrm{NaCNBH}_{3}$. On the other hand, the same hexanal modifications were observed when bovine insulin (A and B peptidic chains) was used as the model system instead of oxidized insulin B chain.
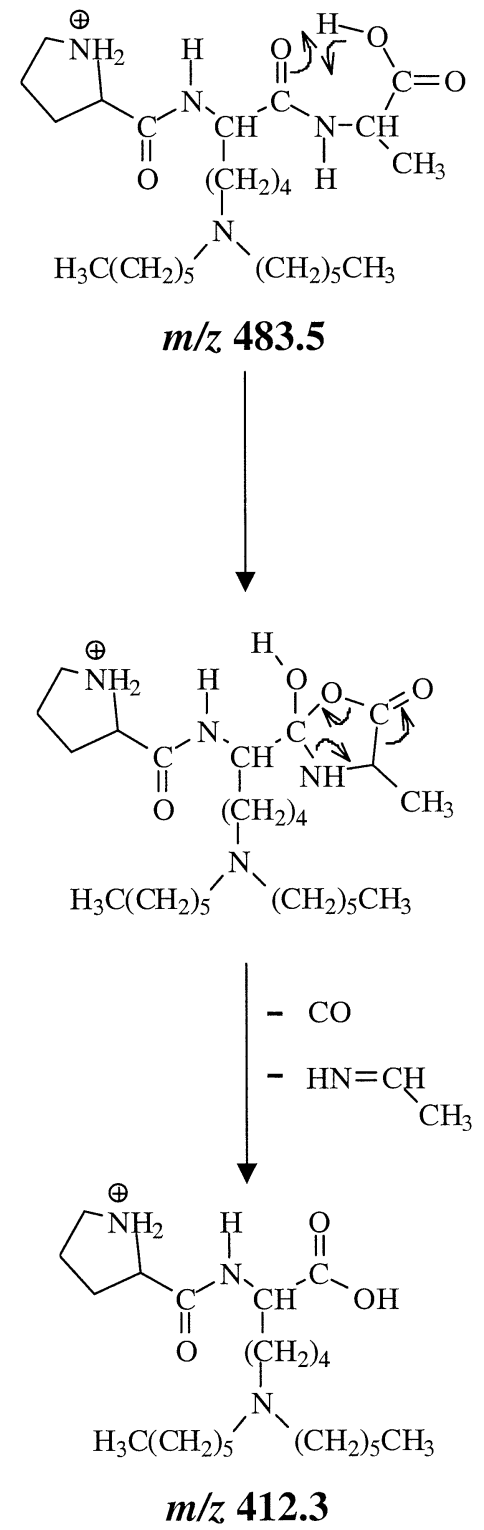

Figure 8. Postulated fragmentation mechanism for the loss of $71 \mathrm{u}$ from "in-source" collision followed by CID experiment obtained by selecting $\mathrm{m} / \mathrm{z} 483.5$.

\section{Conclusions}

The protein modifications generated by lipid oxidation products have been investigated by studying the adducts formed upon reaction of a model peptide: Oxidized insulin B chain and either HNE or hexanal. A procedure for the stabilization of the different model systems, by means of a reducing chemical agent (i.e., $\mathrm{NaCNBH}_{3}$ or $\mathrm{NaBH}_{4}$ ), has also been investigated. With respect to HNE modification, it has been shown that $\mathrm{NaCNBH}_{3}$, when added at the beginning of the incubation, dramatically modified the "natural" mechanism involved in $\mathrm{HNE}$ addition. Indeed, $\mathrm{NaCNBH}_{3}$ appeared to orientate the addition mechanism toward the imine (Schiff base) formation (instead of Michael addition) and thus, as shown by deconvoluted ESI mass spectra 

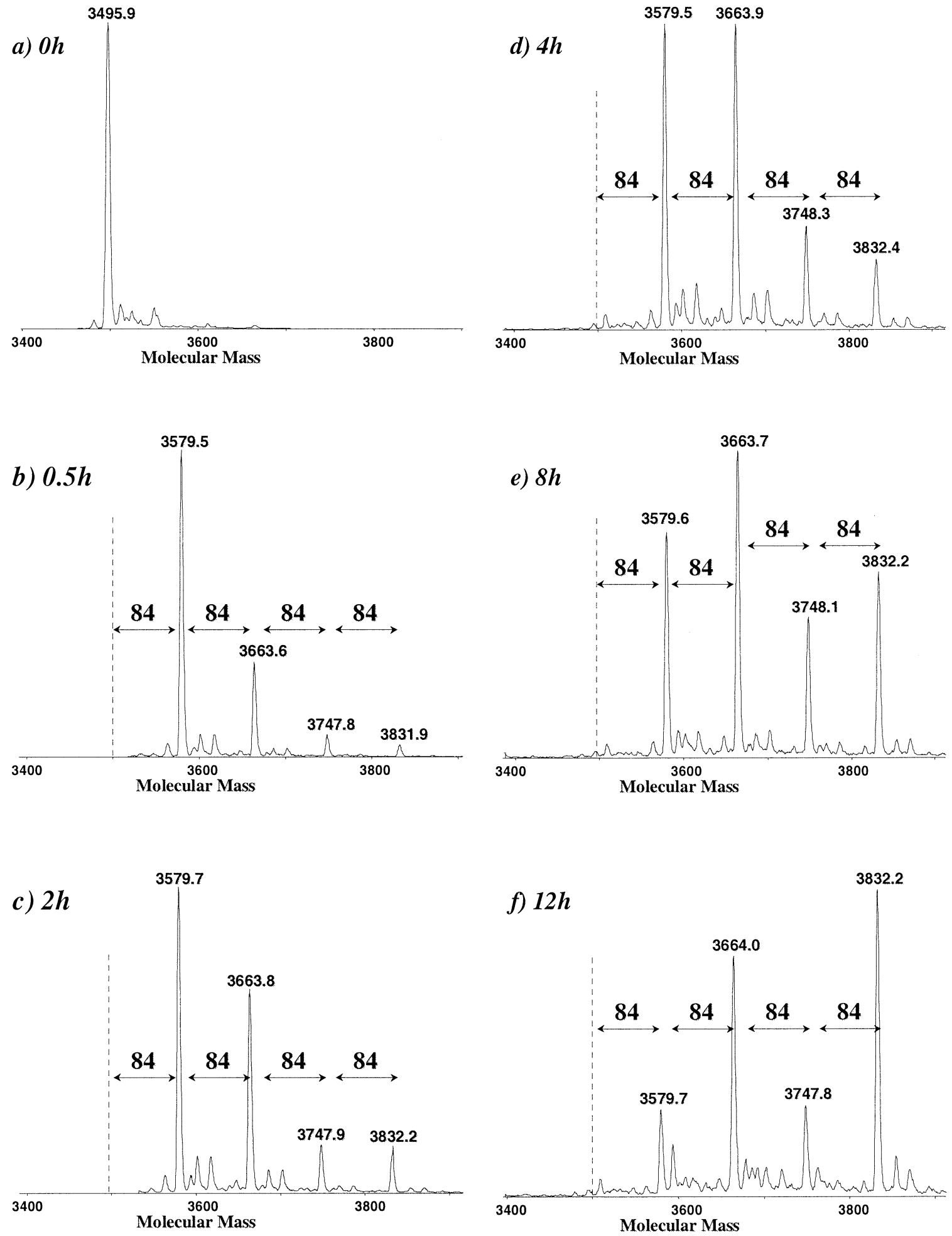

Figure 9. Deconvoluted ESI mass spectra of oxidized insulin B chain incubated with hexanal in the presence of $\mathrm{NaCNBH}_{3}$ for $0,0.5,2,4,8$, and $12 \mathrm{~h}$.

to modify preferentially $\mathrm{N}$-terminal amino acid rather than the histidine residue. More interestingly, sample reduction with $\mathrm{NaBH}_{4}$ reagent prior to analysis enabled a better characterization of the HNE-modified species due to an improved stability of the fragment ions under low collision energy CID conditions, thus giving rise to an intense diagnostic ion at $\mathrm{m} / \mathrm{z} 268$ (immonium ion of modified histidine). Thus, screening for precursor ions of $m / z 268$ can be applied to pull-out HNE-modified peptides on histidine within a crude tryptic digest. Furthermore, in a more global screening approach, tandem mass spectrometry measurements could be 

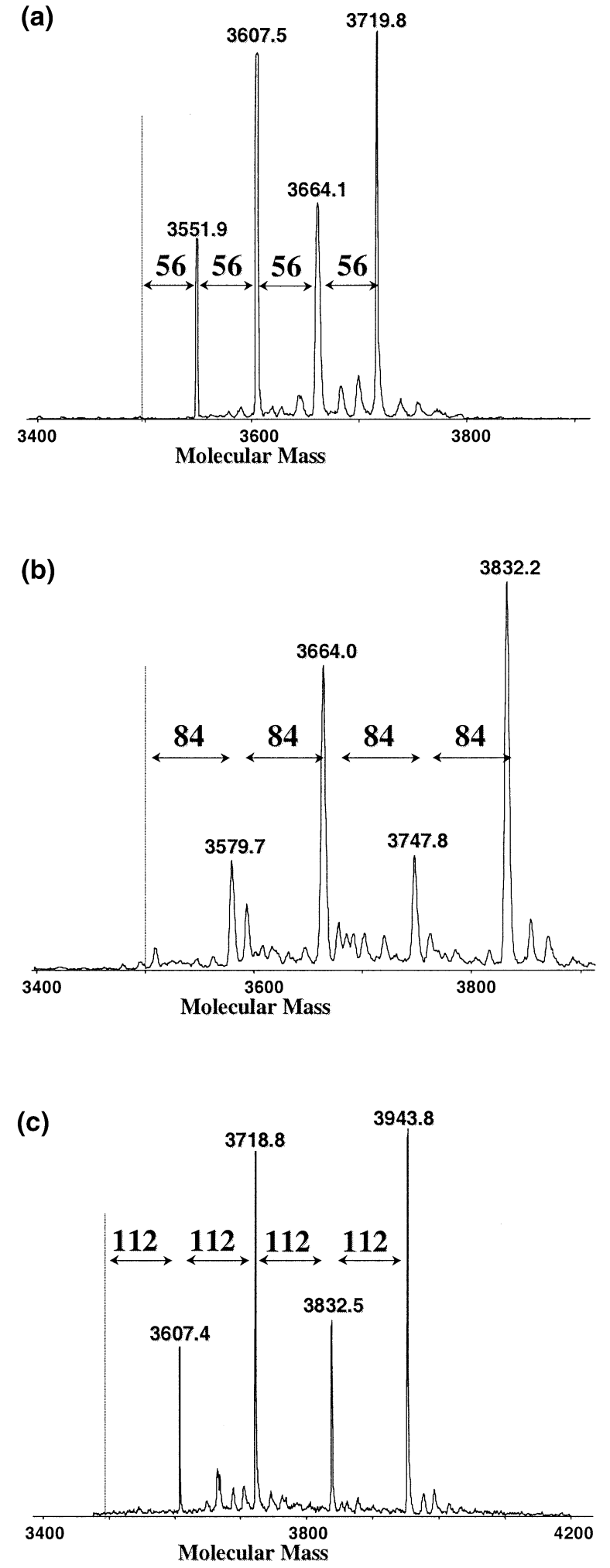

Figure 10. Deconvoluted ESI mass spectra obtained after a $12 \mathrm{~h}$ incubation period of oxidized insulin B chain with (a) butanal, (b) hexanal, and (c) octanal. The experiments were realized in the presence of $\mathrm{NaCNBH}_{3}$.

performed in precursor ion scan mode of $m / z 139$, which corresponds to the protonated dehydrated HNE moiety.
In light of hexanal adduction, $\mathrm{NaCNBH}_{3}$ could be useful for increasing the modification degree of a model peptide without orientating the alkylation toward a certain type of amino acid residue (when oxidized insulin B chain is used). However, the monitoring in precursor ion scan mode of typical fragment ions resulting from hexanal modifications has been assayed but was rather unsuccessful. A more precise study of the modified species by "in-source" collision followed by CID experiments revealed that both $\mathrm{N}$-terminal $\mathrm{Phe}_{1}$ and $\mathrm{Lys}_{29}$ residues were the targets of mono- and further di-alkylation reactions. Due to its high efficiency, this alkylation reaction should be placed under control in order to obtain mono-alkylated model peptides. Such approach could be useful to check if a lysine lateral chain is involved in a certain mechanism or fragmentation pathway.

\section{Acknowledgments}

The authors thank Dr. Richard Stadler, Nestec Ltd., for his valuable comments and helpful discussions.

\section{References}

1. Gray, J. I.; Monahan, F. J. Measurement of Lipid Oxidation in Meat and Meat Products. Trends Food Sci. Technol. 1992, 3, 315-319.

2. Esterbauer, H. Cytotoxicity and Genotoxicity of Lipid-Oxidation Products. Am. J. Clin. Nutr. 1993, 57, 779S-785S.

3. Pokorny, J.; Luan, N. T.; Kondratenko, S. S.; Janicek, G. Changes of Sensory Value by Interaction of Alkanals With Amino Acids and Proteins. Nahrung 1976, 20, 267-272.

4. Stapelfeldt, H.; Skibsted, L. H. Modification of $\beta$-Lactoglobulin by Aliphatic Aldehydes in Aqueous Solution. J. Dairy Res. 1994, 61, 209-219.

5. Zamora, R.; Hidalgo, F. J. Inhibition of Proteolysis in Oxidized Lipid-Damaged Proteins. J. Agric. Food Chem. 2001, 49, 6006-6011.

6. Uchida, K.; Toyokuni, S.; Nishikawa, K.; Kawakishi, S.; Hiroaki, O.; Hiai, H.; Stadtman, E. R. Michael Addition-Type 4-Hydroxy-2-Nonenal Adducts in Modified Low-Density Lipoproteins: Markers for Atherosclerosis. Biochemistry 1994, 33, 12487-12494.

7. Bruenner, B. A.; Jones, A. D.; German, J. B. Direct Characterization of Protein Adducts of the Lipid Peroxidation Product 4-Hydroxy-2-Nonenal Using Electrospray Mass Spectrometry. Chem. Res. Toxicol. 1995, 8, 552-559.

8. Uchida, K.; Stadtman, E. R. Modification of Histidine Residues in Proteins by Reaction With 4-Hydroxynonenal. Proc. Natl. Acad. Sci. U.S.A. 1992, 89, 4544-4548.

9. McGirr, L. G.; Hadley, M.; Draper, H. H. Identification $N^{a}$ Acetyl-e-(2-Propenal)Lysine as a Urinary Metabolite of Malondialdehyde. J. Biol. Chem. 1985, 260, 15427-15431.

10. Nair, V.; Vietti, D. E.; Cooper, C. S. Degenerative Chemistry of Malondialdehyde. Structure, Stereochemistry, and Kinetics of Formation of Enaminals From Reaction With Amino Acids. J. Am. Chem. Soc. 1981, 103, 3030-3036.

11. Burcham, P. C.; Kuhan, Y. T. Introduction of Carbonyl Groups into Proteins by the Lipid Peroxidation Product, Malondialdehyde. Biochem. Biophys. Res. Commun. 1996, 220, 996-1001.

12. Musatov, A.; Carroll, C. A.; Liu, Y. C.; Henderson, G. I.; Weintraub, S. T.; Robinson, N. C. Identification of Bovine Heart Cytochrome c Oxidase Subunits Modified by the Lipid Peroxidation Product 4-Hydroxy-2-Nonenal. Biochemistry 2002, 41, 8212-8220. 
13. Bruenner, B. A.; Jones, A. D.; German, J. B. Maximum Entropy Deconvolution of Heterogeneity in Protein Modification: Protein Adducts of 4-Hydroxy-2-Nonenal. Rapid Commun. Mass Spectrom. 1994, 8, 509-512.

14. Bolgar, M. S.; Gaskell, S. J. Determination of the Sites of 4-Hydroxy-2-Nonenal Adduction to Protein by Electrospray Tandem Mass Spectrometry. Anal. Chem. 1996, 68, 2325-2330.

15. Friguet, B.; Stadtman, E. R.; Szweda, L. I. Modification of Glucose-6-Phosphate Dehydrogenase by 4-Hydroxy-2-Nonenal. Formation of Cross-Linked Protein That Inhibits the Multicatalytic Protease. J. Biol. Chem. 1994, 269, 21639-21643.

16. Grace, J. M.; McDonald, T. L.; Roberts, R. J.; Kinter, M. Determination of Site-Specific Modifications of Glucose-6Phosphate Dehydrogenase by 4-Hydroxy-2-Nonenal Using Matrix-Assisted Laser Desorption Time-of-Flight Mass Spectrometry. Free Radic. Res. 1996, 25, 23-29.

17. Bertand-Harb, C.; Charrier, B.; Dalgalarrando, M.; Chobert, J. M.; Haertlé, T. Condensation of Glycosidic and Aromatic Strutures on Amino Groups of B-Lactoglobulin B Via Reductive Alkylation. Solubility and Emulfying Properties of the Protein Derivatives. Lait 1990, 71, 205-215.

18. Lee, H. S.; Sen, L. C.; Clifford, A. J.; Whitaker, J. R.; Feeney, R. E. Preparation and Nutritional Properties of Caseins Covalently Modified with Sugars. Reductive Alkylation of Lysines With Glucose, Fructose, or Lactose. J. Agric. Food Chem. 1979, 27, 1094-1098.

19. Smith, S. A.; Pestka, J. J.; Gray, J. I.; Smith, D. M. Production and Specificity of Polyclonal Antibodies to Hexanal-Lysine Adducts. J. Agric. Food Chem. 1999, 47, 1389-1395.

20. Bolgar, M. S.; Yang, C. Y.; Gaskell, S. J. First Direct Evidence for Lipid/Protein Conjugation in Oxidized Human Low Density Lipoprotein. J. Biol. Chem. 1996, 271, 27999-28001.

21. Requena, J. R.; Fu, M. X.; Ahmed, M. U.; Jenkins, A. J.; Lyons, T. J.; Baynes, J. W.; Thorpe, S. R. Quantification of Malondialdehyde and 4-Hydroxynonenal Adducts to Lysine Residues in Native and Oxidized Human Low-Density Lipoprotein. Biochem. J. 1997, 322, 317-325.

22. Friguet, B.; Szweda, L. I. Inhibition of the Multicatalytic Proteinase (Proteasome) by 4-Hydroxy-2-Nonenal CrossLinked Protein. FEBS Lett. 1997, 405, 21-25.

23. Refsgaard, H. H.; Tsai, L.; Stadtman, E. R. Modifications of Proteins by Polyunsaturated Fatty Acid Peroxidation Products. Proc. Natl. Acad. Sci. U.S.A. 2000, 97, 611-616.

24. Ulberth, F.; Roubicek, D. Monitoring of Oxidative Deterioration of Milk Powder by Headspace Gas Chromatography. Int. Dairy J. 1995, 5, 523-531.
25. Lehmann, W. D. Single Series Peptide Fragment Ion Spectra Generated by Two-Stage Collision-Induced Dissociation in a Triple Quadrupole. J. Am. Soc. Mass Spectrom. 1998, 9, 606-611.

26. Biemann, K. Contributions of Mass Spectrometry to Peptide and Protein Structure. Biomed. Environ. Mass Spectrom. 1988, 16, 99-111.

27. Cohn, J. A.; Tsai, L.; Friguet, B.; Szweda, L. I. Chemical Characterization of a Protein-4-Hydroxy-2-Nonenal CrossLink: Immunochemical Detection in Mitochondria Exposed to Oxidative Stress. Arch. Biochem. Biophys. 1996, 328, 158-164.

28. Willard, B. B.; Kinter, M. Effects of the Position of Internal Histidine Residues on the Collision-Induced Fragmentation of Triply Protonated Tryptic Peptides. J. Am. Soc. Mass Spectrom. 2001, 12, 1262-1271.

29. Borch, R. F.; Bernstein, M. D.; Durst, H. D. The Cyanohydridoborate Anion as a Selective Reducing Agent. J. Am. Chem. Soc. 1971, 93, 2897-2904.

30. Katta, V.; Chowdhury, S. K.; Chait, B. T. Use of a SingleQuadrupole Mass Spectrometer for Collision-Induced Dissociation Studies of Multiply Charged Peptide Ions Produced by Electrospray Ionization. Anal. Chem. 1991, 63, 174-178.

31. van Dongen, W. D.; Wijk, J. I. T.; Green, B. N.; Heerma, W.; Haverkamp, J. Comparison Between Collision Induced Dissociation of Electrosprayed Protonated Peptides in the Up-Front Source Region and in a Low-Energy Collision Cell. Rapid Commun. Mass Spectrom. 1999, 13, 1712-1716.

32. Harrison, A. G. Energy-Resolved Mass Spectrometry: A Comparison of Quadrupole Cell and Cone-Voltage Collision-Induced Dissociation. Rapid Commun. Mass Spectrom. 1999, 13, 1663-1670.

33. Schey, K. L.; Schwartz, J. C.; Cooks, R. G. Observation of Sequence-Specific Peptide Fragmentation Using Extended Tandem Mass Spectrometry Experiments. Rapid Commun. Mass Spectrom. 1989, 3, 305-309.

34. Thorne, G. C.; Gaskell, S. J. Elucidation of Some Fragmentations of Small Peptides Using Sequential Mass Spectrometry on a Hybrid Instrument. Rapid Commun. Mass Spectrom. 1989, 3, 217-221.

35. Thorne, G. C.; Ballard, K. D.; Gaskell, S. J. Metastable Decomposition of Peptide $[\mathrm{M}+\mathrm{H}]^{+}$Ions via Rearrangement Involving Loss of the C-Terminal Amino Acid Residue. J. Am. Soc. Mass Spectrom. 1990, 1, 249-257.

36. Sadagopan, N.; Watson, J. T. Mass Spectrometric Evidence for Mechanisms of Fragmentation of Charge-Derivatized Peptides. J. Am. Soc. Mass Spectrom. 2001, 12, 399-409. 